\title{
UMA PROPOSTA PARA A CONSTRUÇÃO DO LETRAMENTO LITERÁRIO POR MEIO DA LEITURA DE POEMAS
}

\section{A PROPOSAL FOR CONSTRUCTION OF LITERARY LITERACY BY POEM READING}

\author{
Angela Maria Fernandes Pimenta ${ }^{1}$ \\ Alice Atsuko Matsuda ${ }^{2}$
}

\begin{abstract}
Resumo: Este artigo é parte da dissertação de mestrado intitulada Convite para desvendar enigmas: uma proposta para a construção do letramento literário na leitura de poemas e pretende discutir as contribuições do Método Recepcional e da sequência expandida do Letramento Literário para a formação de leitores de poesia no Ensino Médio. A metodologia utilizada para a organização do estudo foi a abordagem qualitativa do tipo etnográfico. O estudo foi realizado durante os ano letivos de 2017 e 2018, em uma escola da rede estadual de ensino de Campo Largo-PR, durante as aulas de Língua Portuguesa e Literatura para turmas do $4^{\circ}$ ano do Curso de Formação de Docentes para a Educação Infantil e para os anos iniciais do Ensino Fundamental. O estudo descreve e analisa o trabalho realizado, utilizando as 5 etapas do Método Recepcional, organizado por Aguiar e Bordini (1993), e a sequência expandida do Letramento Literário sugerida por Cosson (2009), na leitura de poemas da obra Claro Enigma (1951), de Carlos Drummond de Andrade.
\end{abstract}

Palavras-chave: ensino de literatura; método recepcional; sequência expandida; formação do leitor; leitura de poesia.

\begin{abstract}
This article is part of the master dissertation entitled Invitation to unravel puzzles: a proposal for the construction of literary literacy by poems reading and intends to discuss the contributions of the Receptive Method and the expanded sequence of Literary Literature for the formation of readers of poetry in Teaching Medium. The methodology used to organize the study was the qualitative approach of the ethnographic type. The study was carried out during the 2017 and 2018 school years, in a school of the state school system of Campo Largo-PR, during the Portuguese Language and Literature classes for classes of the 4th year of the Teacher Training Course for Early Childhood Education The study describes and analyzes the work carried out using the 5 steps of the Receptive Method, organized by Aguiar and Bordini (1993),
\end{abstract}

\footnotetext{
${ }^{1}$ Mestre em Estudos de Linguagens pela Universidade Tecnológica Federal do Paraná, professora de Língua Portuguesa e Literatura para o Ensino Médio e Curso de Formação de Docentes no estado do Paraná. E-mail: amfprofessora@yahoo.com.br

${ }^{2}$ Doutora em Letras, em Estudos Literários, pela Universidade Estadual de Londrina (2009), Pós-Doutorado na Universidade de Coimbra, com o Grupo de Investigação em Materialidades da Literatura, com apoio Capes. Professor titular - Adjunto 4 - da Universidade Tecnológica federal do Paraná, Campus Curitiba. Docente Permanente do Programa de Pós-Graduação em Estudos de Linguagens (PPGEL). E-mail: profa.aamatsuda@gmail.com
} 
and the expanded sequence of the Literature Letters suggested by Cosson (2009), in the reading poems from the book Claro Enigma (1951), by Carlos Drummond de Andrade.

Keywords: teaching literature; receptive method; expanded sequence; formation of the reader; reading of poetry

\section{Introdução}

O trabalho com o texto literário encontra muitos entraves na prática diária e o principal deles está na utilização do texto literário como pretexto para o trabalho com conhecimentos gramaticais, além das situações em que o trabalho com a Literatura é substituído por uma série de exercícios envolvendo fragmentos textuais ou textos de crítica literária (e não propriamente de Literatura), trazidos pelos livros didáticos.

Tal prática é questionada por Todorov (2009, p. 15), ao afirmar: "O ensino de Literatura na escola corre perigo". Nas palavras de Todorov, a maneira como a Literatura vem sendo apresentada aos jovens na escola é o grande problema do ensino nas instituições escolares brasileiras, pois eles não entram em contato com os textos literários, mas apenas com a crítica, com a teoria ou com a história literária. Para o filósofo, o texto literário deve voltar a ocupar o centro do processo educativo, pois, somente ele, em toda sua grandeza, será capaz de encantar, emocionar e criar raízes profundas nos leitores.

É inegável, para qualquer professor de Língua Portuguesa e Literatura, o papel dos textos literários na formação humana e social do indivíduo, porém, no cotidiano da escola, aniquilamos essas possibilidades trocando o trabalho com os textos literários pelo trabalho com a crítica sobre eles. A seleção do autor do livro didático torna-se a nossa baliza para selecionar o que se deve ou não se deve ler em sala.

Cosson (2014, p. 30) afirma que a função da Literatura na escola é ensinar-nos a ler melhor e isso ocorre "não apenas porque possibilita a criação do hábito de leitura ou porque seja prazerosa", mas porque ela nos fornece os instrumentos necessários para interagir com proficiência em um mundo construído pela linguagem.

Na prática rotineira da sala de aula, inúmeras vezes percebemos que os estudantes demonstram pouco apreço por atividades de leitura, sejam elas individuais ou momentos de partilha e discussões coletivas sobre os textos lidos. Nota-se, ainda, um discurso recorrente entre os estudantes de que a leitura literária é uma atividade enfadonha e desconectada da vida 
prática. Saber Literatura torna-se, então, sinônimo de saber autores, datas e características de períodos literários e os educadores chegam à triste constatação de que a escola tem fracassado em sua tarefa primordial: a formação de leitores.

A situação torna-se ainda mais grave quando se analisa o trabalho com o texto poético em sala de aula: a poesia apresenta-se como o gênero menos explorado na escola e é relegado a segundo plano, por conta de suas dificuldades de leitura e do baixo interesse apresentado por grande parte dos alunos. Essa realidade do trabalho incipiente com o texto poético em sala de aula (aliada a uma paixão pelo ensino da Literatura) despertou-nos o interesse em realizar esta pesquisa do Mestrado em Estudos de Linguagem a partir de uma proposta que vislumbrasse um caminho diferenciado para a exploração do texto poético com os alunos do último ano do Curso de Formação de Docentes.

Dessa forma, partindo da hipótese de que o trabalho com o texto poético, na perspectiva do Método Recepcional e do Letramento Literário, pode ser uma estratégia profícua para o desenvolvimento da competência literária e para a formação do leitor competente, capaz de construir sentidos para o que lê, ultrapassando a leitura de fragmentos de obras clássicas e a análise utilitária de textos poéticos, no sentido da construção de uma leitura consistente que leve em consideração as semelhanças, diferenças, inter-relações e coexistências num mesmo período literário, ampliando seu horizonte de expectativas, conforme prevê o Método Recepcional (AGUIAR; BORDINI, 1993), aplicamos a sequência de atividades que apresentamos neste artigo.

Na sequência, apresentamos uma breve discussão acerca dos problemas enfrentados pelo ensino de Literatura na escola.

\section{A crise no ensino de Literatura na escola}

Quando se pensa em qualquer prática de ensino de Literatura, "ela é organizada a partir do pano de fundo daquilo que se entende como seu objeto" (DURÃO, 2017, p. 1).

Segundo Durão (2017, p. 20):

A literatura só merece esse nome enquanto for capaz de suscitar questões relevantes
para o nosso presente; se isso não ocorre, ela torna-se documento histórico ou
testemunho social, objeto de outra disciplina ou curiosidade anedótica.

Durão (2017) reafirma que dados como biografia do autor, contexto social, influências ou características de períodos literários só adquirem sentido quando aliados às atividades de 
leitura e interpretação. No entanto, o que predomina nas aulas de Literatura do Ensino Médio é um estudo historiográfico, baseado nas características dos períodos literários, principais autores representativos de cada época e o contexto social, sem leitura das obras literárias. Quando se realiza a leitura, são fragmentos das obras literárias que constam do livro didático dos alunos.

Não se trata de culpabilizar o professor, mas de apontar um aspecto essencial, quando se discute o trabalho com a Literatura: o excesso de aulas que os professores são obrigados a assumir para que isso lhes traga uma condição de vida mais digna, aliado à falta de tempo e de incentivo para a formação continuada que possa complementar sua formação inicial, é responsável por esse quadro.

Segundo Cantarin e Almeida (2017), o professor de Língua Portuguesa e Literatura,

[...] ainda que tenha aprendido as bases da sociolinguística, será mais fácil se dobrar ao ensino de gramática tradicional do que preparar aulas contextualizadas, que incitem o pensamento crítico a respeito das formas de manifestação do preconceito linguístico na sociedade contemporânea; ainda que tenha estudado a Estética da Recepção, será mais simples "ensinar literatura" de acordo com o modelo historicista e positivista que ainda predomina nos livros didáticos. É difícil uma peça nova manter-se sem ferrugem em contato com uma engrenagem enferrujada. (CANTARIN; ALMEIDA, 2017, p. 127)

A despeito de todos os problemas que envolvem o ensino de Literatura na escola, Todorov (2009) defende um princípio ético para a permanência do ensino de Literatura em nossas salas de aula:

Somos todos feitos do que os outros seres humanos nos dão: primeiro nossos pais, depois aqueles que nos cercam; a literatura abre ao infinito essa possibilidade de interação com os outros e por isso, nos enriquece infinitamente. (TODOROV, 2009, p. 24)

Não há métodos que sejam capazes de avaliar a real influência que a Literatura pode causar num indivíduo, porém utilizar uma metodologia que privilegie a experiência estética e a compreensão fruidora do texto literário é o caminho a que nos propomos na investigação aqui apresentada. Segundo Nascimento e Harmuch (2017, p. 87) o "gosto pela literatura é, portanto, consequência de um processo que não pode prescindir do fato de que não é possível gostar daquilo que não se conhece".

O ensino de poesia apresenta certas dificuldades "porque no universo prosaico o meio de expressão nos parece mais próximo da linguagem cotidiana e nos familiarizamos mais rapidamente com ele" (CANDIDO, 1996, p. 11). 
Lajolo (1993) faz alusão à poesia como "uma frágil vítima da escola". Tal situação desfavorável e pouco atrativa da leitura e do ensino de poesia na escola se dá, em grande parte, pela incompatibilidade entre os horizontes de expectativas de professores e dos alunos. $\mathrm{O}$ interesse em transformar o texto poético em um conteúdo, didatizando-o, muitas vezes acaba por causar um crescente desinteresse de leitura entre os jovens em idade escolar.

Zilberman (2008) identifica uma crise no ensino de Literatura, cujos sintomas são a falta de leitura entre os estudantes e o desconhecimento do patrimônio literário nacional. A autora aponta ainda que o vestibular costuma ser o agente determinador daquilo que se estuda ou não em Literatura no Ensino Médio.

Rildo Cosson aprofunda a concepção de crise proposta por Zilberman e anuncia a falência do ensino de literatura, ao abordar alguns equívocos:

\begin{abstract}
Seja em nome da ordem, da liberdade, ou do prazer, o certo é que a Literatura não está sendo ensinada para garantir a função essencial de construir e reconstruir a palavra que nos humaniza. Em primeiro lugar porque falta um objeto próprio de ensino. Os que se prendem aos programas curriculares escritos a partir da história da literatura precisam vencer uma noção conteudística do ensino para compreender que, mais que um conhecimento literário, o que se pode trazer ao aluno é uma experiência de leitura a ser compartilhada. (COSSON, 2014, p. 23)
\end{abstract}

A seguir, de maneira bastante sintética, apresentamos algumas discussões acerca do Método Recepcional e da Sequência Expandida do Letramento Literário, estratégias metodológicas por nós utilizadas para o trabalho aqui apresentado.

\title{
20 Método Recepcional e a Sequência Expandida do letramento literário como métodos de trabalho com o texto poético
}

O Método Recepcional, proposto por Aguiar e Bordini (1993), divide-se em 5 etapas e, dentre os conceitos envolvidos em sua aplicação, destaca-se o conceito de horizonte de expectativas. Tal conceito foi formulado por Jauss e indica o conjunto de valores, normas sociais, experiências, ideologias, expectativas, enfim, as dimensões que constituem o ser e irão compor sua memória literária, formando um horizonte (limite) que poderá ser reformulado, ampliado ou reproduzido, de acordo com o grau de identificação ou distanciamento com a obra literária. 
A primeira etapa denomina-se determinação do horizonte de expectativas. É o momento em que o professor realiza a sondagem dos horizontes de expectativas dos alunos. Após ele estar consciente da realidade da sala em que irá trabalhar, dos conhecimentos que a turma já tem ou não sobre o que será trabalhado, além de verificar o nível de maturidade dos alunos como leitor é que efetivamente o professor poderá preparar suas aulas.

A etapa seguinte é a de atendimento do horizonte de expectativas, proporcionando aos alunos-leitores experiências com os textos literários que satisfaçam as suas necessidades quanto ao tema e estratégias utilizadas, porque lhe são textos familiares.

A terceira etapa, denominada de ruptura do horizonte de expectativas, é o momento em que se exploram textos que apresentam maiores exigências por parte dos alunos. Mantémse um dos aspectos dos textos usados na etapa do atendimento dos horizontes (tema, tratamento, estrutura ou linguagem) e rompe-se com os demais recursos compositivos, de modo que o aluno perceba que os textos apresentados nesse momento são diferentes e exigem mais dele.

$\mathrm{Na}$ etapa seguinte, questionamento do horizonte de expectativas, faz-se a análise comparativa das experiências de leitura dos momentos anteriores, questionando-se o horizonte de expectativas.

A última etapa denomina-se ampliação do horizonte de expectativas. Na etapa final, os sujeitos,

tendo percebido que as leituras feitas dizem respeito não só a uma tarefa escolar, mas ao modo como veem seu mundo, os alunos, nessa fase, tomam consciência das alterações e aquisições, obtidas através da experiência com a literatura. Cotejando seu horizonte inicial de expectativas com os interesses atuais, verificam que suas exigências tornaram-se maiores, bem como sua capacidade de decifrar o que não é conhecido foi aumentada. (AGUIAR; BORDINI, 1993, p. 90-91)

São muitas as contribuições do Método Recepcional para a formação de alunos críticos e com leituras autônomas e compreensivas do texto literário, na medida em que ele assegura que a Literatura precisa romper com sistemas fechados, recusar padrões dominantes e assegurar seu caráter emancipatório. Além disso, após as 5 etapas, inicia-se "uma nova aplicação do método, que evolui em espiral, sempre permitindo aos alunos uma postura mais consciente com relação à literatura e à vida" (MATSUDA, 2008, p. 62).

O Letramento Literário, conforme explorado por Cosson (2009), é o processo de apropriação da Literatura enquanto linguagem. Utilizamos aqui a expressão processo, porque ela pressupõe a ideia de algo contínuo, em ciclos que não se fecham nunca. Sendo assim, o 
Letramento Literário começa na infância, com as primeiras histórias ouvidas e com as canções de ninar e estende-se por toda a vida, ampliando-se a cada romance lido. O termo apropriação refere-se ao ato de tonar algo como seu, de maneira que ele passa a fazer parte da vida e dos seus pensamentos.

Tendo a leitura literária como objetivo principal esse tipo de letramento, Cosson (2009) destaca que a leitura do aluno deve ser discutida, questionada e analisada e defende a construção de uma comunidade de leitores como objetivo maior do Letramento Literário na escola. A proposta que o pesquisador apresenta para os professores consiste em uma sequência básica e uma sequência expandida de trabalho com vistas ao Letramento Literário.

A sequência expandida foi organizada por Cosson (2009) para atender às necessidades dos professores do Ensino Médio, uma vez que, quando esses faziam uso da sequência básica, faltava-lhes o aprofundamento necessário a respeito da questão do trabalho de leitura literária.

A partir dessa constatação, foram propostas alterações na sequência básica, de modo que se atingissem as diferentes aprendizagens do Letramento Literário. Desse modo, "a sequência expandida vem deixar mais evidentes as articulações que propomos entre experiência, saber e educação literária inscritos no horizonte desse letramento na escola" (COSSON, 2009, p. 76).

Na exposição sobre a sequência expandida, Cosson (2009, p. 33) explicita os critérios que geralmente norteiam o professor no momento de escolher uma obra literária para trabalhar com seus alunos. Segundo ele, a escolha se dá pelo ditame dos programas, para seguir o cânone literário ou uma escolha que privilegie a "pluralidade e diversidade de autores, obras e gêneros na seleção de textos".

A primeira etapa da sequência expandida é a motivação, ou "introdução dos alunos no universo do livro a ser lido" (COSSON, 2009, p. 77), como na sequência básica. A etapa da motivação consiste em buscar maneiras de oferecer a obra a ser lida aos alunos.

Após a motivação, sugere-se a introdução, que pode ocorrer pela entrada temática (o assunto principal da obra em questão), pelo aproveitamento do acervo da biblioteca (comparação entre diferentes edições disponíveis) e pela leitura das primeiras páginas da obra em questão. Todas essas formas de introdução podem ser complementadas com "a leitura de prefácios, orelhas e outros textos que constituem a apresentação do livro" (COSSON, 2009, p.80). 
A fase da leitura requer cuidado por parte do professor, uma vez que nesta etapa devem ser combinados os prazos para a sua execução e se ela se dará em classe ou fora da sala de aula. É importante também que o professor estabeleça o que Cosson (2009) denomina intervalos de leitura, sempre permeados por discussões acerca dos trechos já lidos ou explorados.

A etapa seguinte denomina-se primeira interpretação e destina-se a uma apreensão global da obra, cujo objetivo é "traduzir a impressão geral do título, o impacto que ele teve sobre sua sensibilidade de leitor" (COSSON, 2009. p. 83). É importante que a primeira interpretação ocorra em sala para que o aluno possa perceber que as etapas vão ligando-se e que sua leitura individual é parte importante do processo de Letramento Literário.

A contextualização é o momento seguinte da sequência expandida e diz respeito à leitura da obra dentro de sua situação de produção, sendo que, para Cosson (2009), são diversos os contextos dentro dos quais uma obra está inserida e a exploração destes pode ocorrer de forma unitária ou global. Dentre os tipos de contextualização, destacam-se: teórico, histórico, estilístico, poético, crítico, presentificador e temático.

Cosson (2009, p. 91) destaca ainda que as contextualizações devem ser momentos de partilha em grupos e não ações individuais, já que o "objetivo é levar a um aprofundamento compartilhado da leitura".

A segunda interpretação pretende explorar um dos aspectos da obra e não mais a sua compreensão global. A segunda interpretação é realizada concomitantemente à contextualização e sempre exige um registro final que evidencie que a leitura foi aprofundada. Cosson (2009, p. 94) destaca ainda a importância da segunda interpretação seja seguida de um compartilhamento de leitura.

A partir da segunda interpretação, passa-se para o momento das relações textuais, ou seja, a obra em si passa a não ser o foco, mas "as possibilidades de diálogo que toda obra articula com os textos que a precederam ou que lhe são contemporâneos ou posteriores" (COSSON, 2009, p. 94). A expansão pode ocorrer através do diálogo entre várias obras, sendo um trabalho prioritariamente comparativo e pode ser o marco inicial para reinício da sequência básica ou da expandida, servindo de nova motivação.

A seguir, apresentamos, de maneira bastante sintética, a sequência de atividades aplicadas com a obra Claro Enigma (1951) nas turmas do último ano do Curso de Formação de Docentes. 


\section{0 caminho percorrido com os estudantes}

Na primeira aula de aplicação efetiva do projeto, conversamos, informalmente, com os alunos sobre quais seriam os temas favoritos dos filmes a que assistiam, das obras que liam e que, portanto, lhes despertavam o gosto e a atenção, a fim de determinarmos seus horizontes de expectativas.

Como optamos por aplicar o Método Recepcional, com objetivo de introduzir e favorecer a leitura de uma obra de poemas, diminuindo a distância estética entre os alunos e o texto, escolhemos o tema do AMOR para iniciar a aplicação das etapas do método, uma vez que esse é um sentimento complexo e abstrato, estando presente em nossas vidas de diferentes formas. Além disso, essa temática perpassa todas as partes da obra Claro Enigma (1951) a ser explorada posteriormente..

Esta etapa da determinação do horizonte de expectativas é o momento de o professor conhecer os alunos com os quais está trabalhando, seus gostos e preferências, para traçar um projeto de atividades que, em um primeiro momento, atendam a esse horizonte de expectativas. Aguiar e Bordini (1993) mencionam a importância dos alunos sentirem-se representados e respeitados em suas necessidades, interesses e aspirações, ação que visa favorecer a identificação do leitor com a obra que lhe será posteriormente apresentada, mobilizando um encontro significativo.

Em seguida, demos início à segunda etapa do Método Recepcional: o atendimento do horizonte de expectativas, com a exploração da canção Pra você guardei o amor, de Nando Reis.

$\mathrm{Na}$ etapa do atendimento do horizonte de expectativas, o professor deve trazer textos e obras artísticas que estejam próximas da vivência e do gosto já demonstrado pelos alunos. É nesta etapa que serão proporcionados aos alunos textos que atendam às suas concepções e leituras e não surpreendam nem pela forma, nem pelo conteúdo, sendo textos facilmente fruídos e compreendidos.

Na sequência, pedimos que os alunos apontassem canções que também representassem um aspecto considerado importante por eles na relação amorosa. As canções apontadas, salvo algumas exceções, pertencem aos grandes sucessos de massa do momento e algumas são canções em língua inglesa.

Nas aulas seguintes, ainda na etapa do atendimento do horizonte de expectativas, exibimos em sala de aula o filme Se eu ficar, grande sucesso entre o público adolescente nos 
últimos anos, que também fora citado pelos alunos no momento das discussões para a determinação do horizonte de expectativas, como exemplo de filme "emocionante e que traduz o poder do amor" (palavras de TAP). A reação dos alunos não poderia ter sido melhor: "Assistir Se eu ficar na aula de Língua Portuguesa, eu vivi pra ver isso" afirmou a aluna FG.

Concluídas as etapas da determinação e do atendimento do horizonte de expectativas, passamos à etapa seguinte, denominada por Aguiar e Bordini (1993) de ruptura do horizonte de expectativas. Nessa etapa, o professor deve continuar explorando a mesma temática (no caso, a temática amorosa), mas oferecer textos que sejam mais densos e abalem as certezas construídas pelos alunos nas etapas anteriores. Nessa etapa, lemos e discutimos sobre o conto Venha ver o pôr-do-sol, de Lygia Fagundes Telles.

Após a leitura e comentários acerca do conto, solicitamos que os alunos respondessem a algumas questões sobre o enredo e a estrutura do conto. Conforme Aguiar e Bordini (1993, p. 86), o processo de trabalho apoia-se "no debate constante, em todas as suas formas: oral e escrito, consigo mesmo, com os colegas, com o professor e com os membros da comunidade".

Ao iniciarmos a aplicação da etapa do questionamento do horizonte de expectativas, ou seja, o momento em que são comparados e discutidos os textos trabalhados anteriormente, lançamos aos alunos questões para debate oral e para um aprofundamento da etapa do questionamento do horizonte de expectativas, entregamos aos alunos um material impresso com os poemas Se se morre de amor (Gonçalves Dias), Arte de amar (Manuel Bandeira) e Soneto do Amor Total (Vinícius de Moraes). A escolha dos poemas se deu pelo fato de serem produções de autores canônicos, de épocas literárias diferentes, sendo que os três autores já haviam sido trabalhados anteriormente em sala de aula, portanto já eram conhecidos pelos alunos. Após a discussão, pedimos que os alunos registrassem uma síntese da comparação por eles estabelecida entre os poemas.

Para iniciar a etapa da ampliação do horizonte de expectativas e a inserção dos passos do letramento literário, propusemos uma elaboração de cartazes, resumindo as percepções sobre o amor vivenciadas em cada momento até aqui e realizando uma atividade de registro com um tipo diferente de linguagem: uma produção mista, aliando linguagem verbal e não-verbal.

Como parte integrante da etapa da ampliação do horizonte de expectativa, optamos pela leitura da obra Claro Enigma (1951), de Carlos Drummond de Andrade, na perspectiva do letramento literário, a fim de buscar a ampliação da percepção dos alunos sobre o texto literário, especificamente o poético e suas estratégias textuais, uma vez que a obra literária proposta, por 
estar muito distante do horizonte de expectativas dos alunos, de acordo com aquilo que Jauss denomina de "distância estética" permite ampliar a compreensão do fenômeno literário.

Iniciando o trabalho com o Letramento Literário e os passos da sequência expandida proposta por Cosson (2009), a partir da obra Claro Enigma (1951), de Carlos Drummond de Andrade, começamos com aquilo que o autor chama de motivação, ou seja, "uma atividade de preparação, de introdução dos alunos no universo do livro a ser lido" (2009, p. 77). Fizemos ligação, ainda, com a visão do sentimento amoroso, que se modifica no decorrer do tempo, conforme discutido nos textos anteriores. Assim, apresentamos o poema "Quadrilha”, de Carlos Drummond de Andrade, declamado por Paulo Autran e, em seguida, lançamos diversos questionamentos.

Iniciamos a etapa da introdução, definida por Cosson como "uma simples e breve apresentação do autor e da obra" (COSSON, 2009, p. 80), apresentando os dados biográficos de Carlos Drummond de Andrade e contextualizando o autor na chamada "poesia de 1930". Em seguida, apresentamos as edições de Claro Enigma de diferentes editoras e lemos com os alunos a apresentação da "orelha" da edição da Companhia das Letras (2012) que foi o material disponibilizado para fotocópias.

Cosson (2009) sugere que a leitura de uma obra no trabalho com o letramento literário seja feita em intervalos de leitura. Sendo assim, delimitamos 4 intervalos de leitura. Os alunos iniciaram a leitura da obra pela parte denominada Notícias amorosas, a fim de aproveitarmos as questões já discutidas sobre o amor em todos os passos do Método Recepcional. Na medida em que as partes da obra foram sendo lidas pelos alunos em atividades extraclasse ou em leituras dialogadas na sala-de-aula, as demais etapas do letramento literário aconteceram concomitantemente.

Na etapa da primeira interpretação definida por Cosson (2009, p.83) como "a apreensão global da obra", propusemos aos alunos, conforme sugere Cosson, que pensássemos juntos no paradoxo que compõe o título da obra: como um enigma pode ser claro? Cosson (2009) sugere que essa etapa seja iniciada e concluída em apenas uma aula e assim o fizemos. As percepções dos alunos já apontavam para um progresso na sua compreensão leitora. Após a leitura e as discussões realizadas sobre a primeira parte da obra Claro Enigma (1951), enquanto os alunos realizavam a leitura das demais partes da obra, foram aplicadas as diferentes maneiras de contextualização propostas por Cosson (2009). 
Na medida em que os intervalos de leitura propostos eram atendidos, exploramos a etapa que Cosson $(2009$, p. 92) denomina de segunda interpretação da obra, cujo objetivo é a "leitura aprofundada de um de seus aspectos", pois o estudioso adverte que a segunda interpretação ocorre juntamente com a contextualização. Portanto, ao iniciar cada intervalo de leitura, realizamos as diferentes formas de contextualização.

Na segunda interpretação, retomamos as discussões realizadas sobre o amor desde as aulas iniciais, verificando a maneira como essa temática se fazia presente em cada uma das partes do livro, analisadas em sua totalidade. As atividades realizadas pelos alunos, desde as análises individuais, passando pelas discussões e registros em grupos, a criação de canções e de representações verbais e não-verbais sobre o poema "A máquina do mundo", por exemplo, constituem o que Cosson defende como registro final, ou seja, um momento que evidencia o aprofundamento da leitura realizado pelos alunos.

A etapa da expansão do Letramento Literário proposta por Cosson (2009, p. 94) "busca destacar as possibilidades de diálogo que toda obra articula com os textos que a precederam ou que lhe são contemporâneos ou posteriores".

$\mathrm{Na}$ expansão, trabalhamos também com análise de poemas de outros autores pertencentes à segunda fase do Modernismo brasileiro, tais como Cecília Meireles, Mário Quintana e Vinícius de Moraes, além da leitura de outras obras de poemas que estavam em listas de vestibulares, tais como Poemas escolhidos, de Gregório de Matos e Últimos Cantos, de Gonçalves Dias.

Como "a expansão é um diálogo que o leitor constrói entre duas ou mais obras" (COSSON, 2009, p. 95), a leitura dessas obras poéticas de outras épocas e de outros autores foi realizada de maneira comparativa com a obra de Drummond e as etapas da sequência expandida desenvolvidas com a obra Claro Enigma favoreceram a compreensão desses outros textos literários, conforme se pode perceber nas palavras do aluno ENS: "Nessas semanas, vivenciei aulas completas e de qualidade, aulas realmente significativas pra mim e, principalmente, desenvolvi um amor por poemas que eu não sabia que tinha. Hoje leio e entendo os poemas, coisa que não imaginei ser possível”.

\section{Conclusões e novas reflexões}

A escola é a principal instituição responsável pela formação de leitores. A concepção de leitura que o professor possui é responsável por guiar toda a sua prática pedagógica. 
Reafirmamos que, nesta análise, compreende-se a leitura como interação, atitude que prevê e exige a participação do leitor na produção de significados. Dentro dessa concepção, para se formar leitores, não basta que os indivíduos saibam ler, é preciso que eles façam uso social dessa habilidade, tornando-se letrados. Segundo Soares (2003), há estudos que comprovam que um indivíduo letrado modifica sua forma de falar, escrever, amplia seu vocabulário e as estruturas linguísticas que utiliza.

Formar um leitor literário é uma tarefa árdua, em primeiro lugar pela questão do gosto e do prazer pela leitura que deve ser construído desde a mais tenra idade, ainda na família ou nos anos iniciais da escolaridade, em um processo contínuo. Sendo assim, pode-se dizer que o Letramento Literário ocorre durante toda a vida do indivíduo.

Para Cosson, o Letramento Literário possui uma configuração especial diante dos demais tipos de letramento:

\begin{abstract}
Pela própria condição de existência da escrita literária [...] o processo de letramento que se faz via textos literários compreende não apenas uma dimensão diferenciada do uso social da escrita, mas também, e, sobretudo, uma forma de assegurar o seu efetivo domínio. Daí sua importância na escola, ou melhor, sua importância em qualquer processo de letramento, seja aquele oferecido pela escola, seja aquele que se encontra difuso na sociedade. (COSSON, 2009, p. 12)
\end{abstract}

Segundo Eagleton (1997, p. 118), o processo de leitura modifica o ser humano de maneira inegável, pois "à medida que prosseguimos a leitura, deixamos de lado suposições, revemos crenças, fazemos deduções e previsões cada vez mais complexas: cada frase abre um horizonte que é confirmado, questionado ou destruído pela frase seguinte".

A Literatura é primordial para a formação humana, e nesse sentido, as conclusões dessa pesquisa permitem dialogar com as ideias de Antonio Candido (1995), no ensaio $O$ direito à literatura. Nele, o crítico defende que a arte das palavras é um direito humano, uma necessidade básica de todas as pessoas e que "não há povo e não há homem que possa viver sem ela, isto é, sem a possibilidade de entrar em contato com alguma espécie de fabulação" (CANDIDO, 1995, p. 246).

Candido, portanto, atribui à Literatura um poder humanizador, uma vez que ela ordena em palavras o caos que nos habita. Iser (1999, p. 42) afirma que a "leitura simula a vida, não para retratá-la, mas para permitir que ao leitor que dela participe”. De acordo com Iser, através da leitura o leitor pode sair de seu próprio mundo e penetrar em outros tempos e espaços nos quais pode vivenciar extremos de prazer ou dor, sem sofrer as consequências do mundo real. 
Calvino (1995, p. 11) também reafirma sua confiança na Literatura, indicando valores que só ela, com seus meios específicos, pode nos dar: leveza, rapidez, exatidão, visibilidade e multiplicidade.

Verifica-se, portanto, a importância da Literatura por meio dos teóricos citados. Dessa forma, como ensinar Literatura é uma questão primordial, uma metodologia de ensino faz-se necessária para o professor poder sistematizar sua prática, visualizar um norte e um resultado. Assim, o Método Recepcional, que objetiva ampliar os horizontes dos estudantes e instigá-los a buscar novos textos mais complexos que os já lidos por eles, demonstra ser uma metodologia eficaz. A metodologia, por apresentar um caminho cíclico em espiral, funciona como fomentador de leituras. Além disso, para que a experiência recepcional se efetive, deve haver uma quebra de paradigmas nos aprendizes e isso deve ocorrer por meio de obras emancipadoras que questionem os horizontes de expectativas dos alunos. A resistência do jovem à leitura de poemas tende a diminuir na medida em que ele sente que aquilo que está lendo comunica-se emocionalmente, em algum grau, com sua história pessoal ou com seu mundo particular, conforme pode ser constatado nas falas dos alunos envolvidos nas duas situações de aplicação do projeto.

Sabe-se que, muitas vezes, os alunos rejeitam aquilo que desconhecem e isso pode ocorrer quando se oferecem para leitura textos que rompem com o rotineiro e com seu horizonte de expectativas, mas nesse momento é que destacamos o papel do professor de Literatura: conduzindo e esclarecendo a leitura junto com o aluno.

Sabemos que existem inúmeros estudos sobre o assunto que nos propusemos a apresentar neste artigo, porém acreditamos que o campo ainda é vasto, uma vez que as dificuldades para a formação de leitores persistem em todos os níveis de escolaridade e, para isso, não existem fórmulas mágicas ou receitas infalíveis, bem como nenhuma pesquisa trará todas as respostas possíveis.

Sendo assim, o trabalho com a sequência expandida do Letramento Literário e as etapas do Método Recepcional constituíram-se estratégias eficientes, ainda que com suas limitações, na construção de um repensar do ensino de Literatura que ultrapasse o "engessamento" dos manuais didáticos e um caminho possível para a consolidação da capacidade leitora entre os jovens concluintes do Ensino Médio. 


\section{Referências}

AGUIAR,V.T.; BORDINI, M.G. Literatura e formação do leitor: alternativas metodológicas. Porto Alegre: Mercado Aberto, 1993

CANDIDO, A. O direito à literatura. In: Vários escritos. Rio de Janeiro: Ouro sobre azul / São Paulo: Duas cidades, 2004.

CANDIDO, A. A literatura e a formação do homem. Ciência e cultura. São Paulo. USP, 1972.

CANDIDO, A. Inquietudes na poesia de Drummond. In: Vários escritos. São Paulo: Duas Cidades, 1970.

CANTARIN, M. M.; ALMEIDA, R. C. Da burocracia institucional à ontologia do objeto: notas sobre o ensino (fora do lugar) de literatura. In: CECHINEL e SALES. (Org.). O que significa ensinar literatura. EdUFSC, Florianópolis, 2017

COLOMER, T. Andar entre livros: a leitura literária na escola. Trad. Laura Sandroni. São Paulo: Global, 2007

COMPAGNON, A. O demônio da teoria: Literatura e senso comum. 2 ed. Tradução de: MOURÃO, C. P. B.; SANTIAGO, C. F. Belo Horizonte: Ed. UFMG, 2010.

COMPAGNON, A. Literatura: para quê? Trad. Laura Brandini. Belo Horizonte: Ed UFMG, 2009

COSSON, R. Letramento literário: teoria e prática. São Paulo: Contexto, 2009

COMPAGNON, A. Círculos de leitura e letramento literário. São Paulo: Contexto, 2014

DALLA-BONA, E. M. Letramento literário: ler e escrever literatura nas séries iniciais do ensino fundamental, 2012, 334 f. Tese (Doutorado em Educação) - Programa de PósGraduação em Educação, Universidade Federal do Paraná, Curitiba, 2012

DURÃO, F. A. Da intransitividade do ensino de literatura. In: CECHINEL e SALES. (Org.). $O$ que significa ensinar literatura. EdUFSC, Florianópolis, 2017

EAGLETON, T. Fenomenologia, hermenêutica, teoria da recepção. In: Teoria da literatura: uma introdução. São Paulo: Martins Fontes, 1997

ECO, U. Obra aberta: forma e indeterminação nas poéticas contemporâneas. 8. ed. São Paulo: Perspectiva, 1969

ECO, U. Sobre a literatura. Rio de Janeiro: Record, 2003

FLUSSER, V. Língua e realidade. São Paulo: Herder, 1963

ISER, W. O ato da leitura: uma Teoria do Efeito Estético. Vol. 1. Tradução de J. Kretschmer. São Paulo: Editora 34, 1996.

ISER, W. Teoria da Recepção: reação a uma circunstância histórica. In: ROCHA, J.C. Teoria da ficção: indagações à obra de Wolfgang Iser. Rio de Janeiro: EdUERJ, 1999, p 20-33 
ISER, W. O jogo do texto. In: LIMA, L.C. A literatura e o leitor: textos de estética da recepção. 2ed., Rio de Janeiro: Paz e Terra, 2002, p 105-118

JAUSS, H. R. A história da literatura como provocação à teoria literária. São Paulo: Ática, 1993

LAJOLO, M. Do mundo da leitura para a leitura do mundo. 3. ed. São Paulo: Ática, 1993

MATSUDA, A. A. Tecendo aula de português. In OLIVEIRA, V. da S. (Org.). Educação Literária em Foco: entre teorias e práticas. Disponível em: http://www.faficop.br/dirposgrad/crelit/docs/eb-educliter.pdf. Acesso em: jul. 2019.

MATSUDA. A. A.; PIRES, A. C. da C. Formação do leitor: dificuldades e desafios. Revista Práticas de Linguagem. v. 3, n. 2, jul./dez. 2013

MERQUIOR, J. G. Verso Universo em Drummond. Rio de Janeiro: José Olympio, 1975.

NASCIMENTO, N.; HARMUCH, R. Literatura e ensino nos currículos de Letras. In: CECHINEL e SALES. (Org.). O que significa ensinar literatura. EdUFSC, Florianópolis, 2017

PAULINO, G. Letramento literário: por vielas e alamedas. Revista da FACED, Salvador, n.5, p 117-125, 2001

SILVA, C. S. Poesia na sala de aula e formação do leitor. Anais do Congresso de Leitura do Brasil. Campinas: ALB, 2009.

SILVA, E. T. da. Literatura e pedagogia: ponto e contraponto. Porto Alegre: Mercado Aberto, 1990

TODOROV, T. A literatura em perigo. Trad. Caio Meira. Rio de Janeiro: DIFEL, 2009

Recebido em 18 de julho de 2019. Aceito em 23 de setembro de 2019. 